\title{
The effects of overwintering, sex, year, field identity and vegetation at the boundary of fields on the body condition of Anchomenus dorsalis (Coleoptera: Carabidae)
}

\author{
ELIŠKA BARANOVSKÁ ${ }^{1}$, Michal KNAPP ${ }^{1}$ and PAVEL SASKA ${ }^{1,2}$ \\ ${ }^{1}$ Department of Ecology, Faculty of Environmental Sciences, Czech University of Life Sciences Prague, Kamýcká 129, \\ Praha 6 - Suchdol, CZ-165 21, Czech Republic; e-mails: ElisBee@seznam.cz; kapon@atlas.cz \\ ${ }^{2}$ Functional Biodiversity Group, Crop Research Institute, Drnovská 507, Prague - 6 Ruzyně, CZ-161 00, Czech Republic; \\ e-mail: saska@vurv.cz
} Key words. Coleoptera, Carabidae, Anchomenus dorsalis, agroecosystem, body condition, energy reserves, ground beetles,
spatiotemporal variability

\begin{abstract}
Body condition, in terms of body mass corrected for structural body size, represents an animal's energetic reserves and is an indicator of the health and fitness of an organism. This study investigates the variability in the body condition of the carabid beetle, Anchomenus dorsalis, in time and space at a small scale. The beetles were collected in four fields with two types of boundary (grassy and forest) near Prague-Suchdol in autumn 2009 and 2010 and in spring 2010 and 2011. Body condition was significantly affected by overwintering (the body condition of post-overwintering individuals collected in spring was worse than that of pre-overwintering individuals collected in autumn), sex (females were in better condition than males) and to a lesser extent by sampling year, field identity and several interactions, e.g., overwintering: sex (greater decrease in body condition during overwintering in males than in females), overwintering : year (difference in body condition between pre-overwintering and post-overwintering individuals was greater in 2009/2010 than 2010/2011). Type of boundary had no substantial effect on the body condition of $A$. dorsalis. This study shows the importance of sampling body condition several times a year for more than one season, which has rarely been performed to date.
\end{abstract}

\section{INTRODUCTION}

Body condition indicates the energy (fat) reserves of an animal (Peig \& Green, 2009; Knapp \& Knappová, 2013) and is presumed to substantially influence the fitness of particular organisms. In general, females in good condition mate more frequently with high-quality males (Cotton et al., 2006), have a higher fecundity (Bommarco, 1998b; Moya-Laraño, 2002) and survive better in unfavourable environments (Petersen, 1999) than females in poor condition.

Variation in body condition can be caused either by "strategic" factors (Elkin \& Reid, 2005) or "environmental" factors (van Dijk, 1994). Strategic factors are incorporated in the life cycle of a species and individuals are able to adaptively shape them. Variation in body condition due to strategic factors represents an animal's response to predictable conditions. An example of such a strategic factor is maximisation of food intake before hibernation (van Dijk, 1994; Lövei \& Sunderland, 1996) or sex-specific body condition. Female carabids have higher food demands than males, at least before reproduction (Bilde \& Toft, 1998), because egg production required more energy than sperm production. On the other hand, environmental factors are unpredictable and occur at random in time and space. The course of the weather or disruptive changes in the environment, such as soil operations or pesticide treatments (Östman et al., 2001; Östman, 2005), are environmental factors that can affect the body condition of insects.
Environmental factors are assumed to be responsible for a substantial proportion of the spatial and temporal variation in body condition, of which the uneven distribution of prey in time and space may be the most important (Bommarco, 1998a; Östman et al., 2001). At the farm scale, food availability for carabid beetles can be affected by extreme weather conditions or drastic agronomical practice (Huusela-Veistola, 1996; Bilde \& Toft, 1998). For example, carabid beetles starve less in June than July, most likely a result of the hot and dry weather in the latter month, which may reduce the amount of available prey (Bilde \& Toft, 1998). Increased prey abundance not only positively affects the body condition of males and females of carabid beetles but also increases oocyte numbers (Haschek et al., 2012) or extends the oviposition period (Sota, 1985). Sufficient fat reserves may also be important for prolonged survival after hibernation in early spring, when prey is temporarily scarce (Petersen, 1999).

As predatory carabid beetles often starve in arable fields (Bilde \& Toft, 1998; Bommarco, 1998b), their body condition provides information about the quality of this habitat for particular species (Barone \& Frank, 2003). In addition to local environmental conditions, the body condition of carabid beetles seems to be affected by the surrounding landscape. Crop diversity and high perimeter-to-area ratio (i.e., landscapes with more abundant field boundaries; Östman et al., 2001) both affect the availability of prey for carabid beetles (Haschek et al., 2012). Thus, a heterogeneous landscape may provide a better environment with more 


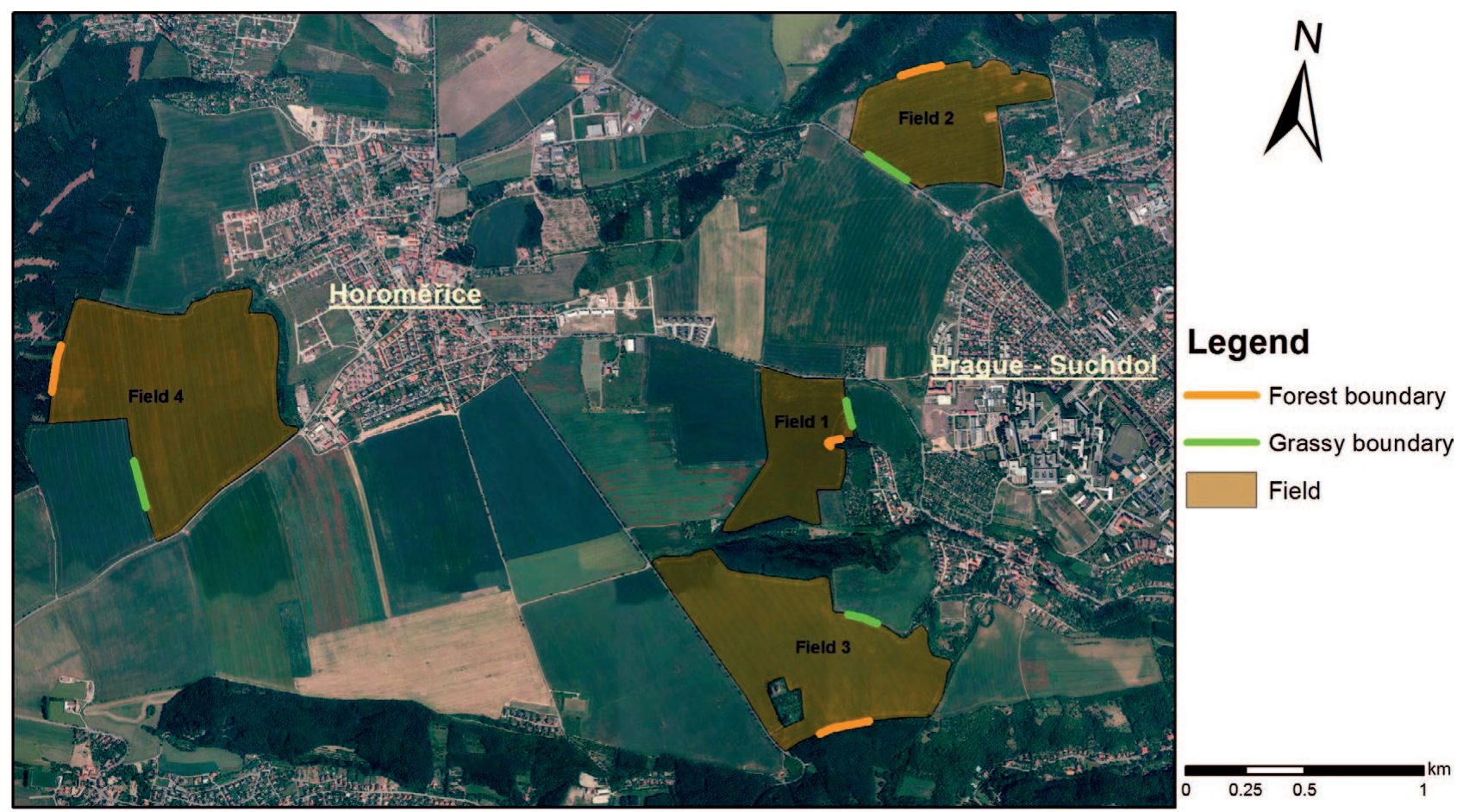

Fig. 1. Map of localities investigated in this study. The arable fields investigated were situated near Prague-Suchdol, in the Czech Republic (GPS coordinates of field centres: field $1-50^{\circ} 7^{\prime} 46.942^{\prime \prime} \mathrm{N} 14^{\circ} 21^{\prime} 37.574^{\prime \prime} \mathrm{E}$, field $2-50^{\circ} 8^{\prime} 28.480^{\prime \prime} \mathrm{N} 14^{\circ} 21^{\prime} 54.754^{\prime \prime}$, field $3-50^{\circ} 7^{\prime} 16.933^{\prime \prime} \mathrm{N} 14^{\circ} 21^{\prime} 44.419^{\prime \prime} \mathrm{E}$, field $\left.4-50^{\circ} 7^{\prime} 38.451^{\prime \prime} \mathrm{N} 14^{\circ} 19^{\prime} 30.361^{\prime \prime} \mathrm{E}\right)$. Orange and green lines mark the sites where pitfall traps were set. The map background was taken from an aerial photograph provided by the Czech Office for Surveying, Mapping and Cadastre (ČÚZK, 2014).

food, resulting in increased fat reserves of carabids and higher population densities (Holland, 2002). Field boundaries are also important, especially for carabid reproduction (Zangger et al., 1994) and overwintering (Andersen, 1997).

Most studies concerning carabid body condition investigate spatial variation or temporal variation separately. To our knowledge, the exception for carabids is the study performed by Östman (2005), who investigated variation in structural body size and body condition on 10 farms around Uppsala, Sweden in two subsequent years. He found asynchronous temporal variation in body condition among sites, suggesting that body condition is affected also by other factors than those related to site characteristics. Recently, Baranovská \& Knapp (2014) investigated the variation in structural body size of two species of carabids in arable fields. They found that structural body size, which is determined during pre-imaginal development and remains stable during adult life, is mainly affected by gender and to a lesser extent also by field identity, year and overwintering. Both studies showed that it is important to study spatial and temporal variation together because there may be an interaction between spatial and temporal variation that affects body condition (Östman, 2005) or structural body size (Östman, 2005; Baranovská \& Knapp, 2014). Moreover, there is no information on the effect of spatial differences in intra-seasonal temporal variation (pre- vs. post-winter) in determining carabid body condition.

In this study, we examined the temporal and spatial variation in the body condition of the polyphagous predatory carabid $A$. dorsalis at eight different sites (four arable fields and two types of boundary within each field) over two seasons (autumn 2009 and spring 2010, autumn 2010 and spring 2011). The same study design was used as in our previous study (Baranovská \& Knapp, 2014), in which we only investigated structural body size. In this paper, we study the variation in body condition of $A$. dorsalis. Unlike structural body size, body condition (here, the dry body mass corrected for structural body size) is substantially affected by the environmental conditions experienced by the adults. First, we investigated how body condition varied among fields, which differed in their properties (area, shape etc.) and in surrounding landscape parameters, which can affect the food supply for the beetles. We also expected that the body condition of $A$. dorsalis would be better in autumn than in spring, as energy reserves will be spent during winter, and females would have better body condition than males because of sex-specific selection pressure on accumulating energy reserves (females have to be prepared for reproduction, which has a high energy cost). Finally, we investigated whether there was any variation in the body condition of $A$. dorsalis between years associated with the variation in environmental conditions in particular seasons.

\section{MATERIAL AND METHODS}

\section{Study species}

Anchomenus dorsalis (Pontoppidan, 1763) is a medium-sized ground beetle (Coleoptera: Carabidae), ca. 5.6-7.7 mm long (Hưrka, 1996). In the Czech Republic, this species occurs in open habitats and is common even in intensively managed agricultural landscapes. Although A. dorsalis occurs within arable fields, surrounding field boundaries are very important for its re- 
production and overwintering (Holland et al., 2009; Roume et al., 2011). Beetles mate and lay eggs in spring and early summer, larval growth takes place during summer, and the new adults that emerge in late summer or early autumn need to feed intensively before overwintering. A. dorsalis is an important generalist predator feeding on aphids and other arthropod crop pests (Wratten \& Vickerman, 1985; Bilde \& Toft, 1997) and is thus considered a beneficial organism with biocontrol potential (Zaller et al., 2009).

\section{Experimental design}

Beetles were collected repeatedly in four arable fields situated a few kilometres northwest of Prague, the Czech Republic (Fig. 1 ). The fields were conventionally managed during the sampling period (autumn 2009 - spring 2011). The fields investigated were located 1-3 km from each other and were surrounded mainly by fragments of forest and other arable fields (separated by grassy boundaries or roads with a grassy ditch). Within each field, six gutter pitfall traps were set (for details see Baranovská \& Knapp, 2014), three at the edge adjacent to a fragment of forest and three at the edge adjacent to a grassy boundary. The traps lacked preservative because it can alter body mass (Knapp, 2012), which would have biased our data. Samples were collected every other day to minimise predation within the pitfall traps. Beetles were collected in autumn (October) 2009 and 2010 and in spring (April) 2010 and 2011. In each field and sampling period, we tried to collect 80 specimens of $A$. dorsalis (40 from the grassy boundary and 40 from the forest boundary). Live beetles were transported to the laboratory, frozen and stored at $-20^{\circ} \mathrm{C}$ until processed. The specimens were sexed and 30 males and 30 females ( 15 per each type of boundary) were selected at random for each field and sampling period. If there were fewer than 15 males or 15 females per particular sampling site (type of boundary within a particular field), then all specimens collected were used. The beetles were dried for $48 \mathrm{~h}$ at $50^{\circ} \mathrm{C}$ and were then weighed using a Sartorius analytical laboratory balance with a precision to $10^{-5} \mathrm{~g}$. Elytron length, hind femur length and pronotum width were measured using a digital calliper with a precision to $0.01 \mathrm{~mm}$. Although it is common practice to take only one measurement (e.g., Bommarco, 1998a; Östman, 2005), it has recently been shown that measuring of more than one dimension is meaningful for carabids due to violated structural isomorphy among the specimens (Knapp \& Knappová, 2013). In total, 936 individuals of Anchomenus dorsalis were weighed, measured and analyzed.

To compare the course of the temperature experienced during the two subsequent winters (2009/2010 and 2010/2011), temperature data were obtained from the weather station of the Crop Research Institute (Prague-Ruzyně; http://www.vurv.cz/meteo/). Temperature measurements were made at the surface of the soil and recorded at hourly intervals.

\section{Statistical analyses}

Several methods of estimating body condition are used in ecological studies, e.g., Fulton's index, Quételet's index, Relative condition, Relative mass, Residual index, Scaled mass index and ANCOVA (Peig \& Green, 2010). In this study, body condition was computed as body mass (dry mass) corrected for structural body size as suggested by García-Berthou (2001). Principal component analysis (PCA) was used to integrate the three measures of structural size (elytron length, pronotum width, hind femur length) into one variable. All specimens were pooled across all sampling sites and all sampling periods and analyzed using a single analysis. Sample scores on the first axis (corresponding to the structural body size of a particular specimen) were then used as co-variables in subsequent univariate analyses of body condition.
The PCA was performed in Canoco for Windows 4.5 software (ter Braak \& Šmilauer, 2002).

To analyse the effects of sex, field, year, overwintering, and boundary type and their interactions on the body condition of A. dorsalis, a generalised linear model with gamma distribution of errors (GLM-g) was employed. Gamma distribution of errors was used because our data were not normally distributed and this distribution is generally appropriate for data based on size measurements (e.g., length, weight). Structural body size (scores on the first axis resulting from PCA) was used as the covariable in the model. Dry body mass of particular specimen was used as the response variable in the model. To identify significant terms, a manual backward selection procedure based on deletion tests (F-tests) was employed. At first, a full model containing all main effects and all their possible interactions was constructed. Subsequently, the full model was simplified by omitting non-significant terms (deletion test; $\mathrm{P}>0.05$ ). Terms were tested (and omitted) in the following order: four-way interactions, three-way interactions, two-way interactions and main terms. The analysis was performed using R 3.0.1 software (R Core Team, 2013).

\section{RESULTS}

Strategic factors had substantial effects on the body condition of Anchomenus dorsalis in this study. Overwintering was the most important factor determining body condition in $A$. dorsalis (Table 1). Pre-overwintering individuals collected in autumn were in significantly better body condi-

TABLE 1. Effects of site, year, overwintering, boundary and sex on body condition in Anchomenus dorsalis. Final generalised linear model with gamma distribution of errors is presented. The final model was selected based on a backward selection procedure applied to the full model consisting of the following explanatory variables (terms): sex, field, overwintering, year, boundary and all possible interactions. The score on the first axis of the PCA based on elytron length, pronotum width and hind femur length measurements of particular specimens was used as a covariable (size) in the model to correct dry body mass for structural body size.

\begin{tabular}{lrrrr}
\hline Term & Df F-value & P-value & $\mathrm{R}^{2}$ \\
\hline size & 1 & 1201.53 & $<0.001$ & 0.382 \\
overwintering & 1 & 765.50 & $<0.001$ & 0.244 \\
sex & 1 & 45.90 & $<0.001$ & 0.015 \\
field & 3 & 3.46 & 0.016 & 0.003 \\
year & 1 & 4.31 & 0.038 & 0.001 \\
boundary & 1 & 0.74 & 0.390 & 0.000 \\
overwintering : sex & 1 & 16.38 & $<0.001$ & 0.005 \\
overwintering : field & 3 & 8.64 & $<0.001$ & 0.008 \\
overwintering : year & 1 & 18.11 & $<0.001$ & 0.006 \\
field : year & 3 & 6.55 & 0.000 & 0.006 \\
field : boundary & 4 & 4.14 & 0.003 & 0.005 \\
overwintering : sex : year & 2 & 3.66 & 0.026 & 0.002 \\
overwintering : field : year & 3 & 6.12 & 0.000 & 0.006 \\
overwintering : field : boundary & 4 & 11.44 & $<0.001$ & 0.015 \\
field : year : boundary & 4 & 5.60 & 0.000 & 0.007 \\
overwintering : field : year : boundary & 4 & 2.81 & 0.025 & 0.004 \\
\hline
\end{tabular}

\#There was no significant main effect of boundary type (P > $0.05)$; however, the term had to be included in the final model because of significant field : boundary, overwintering : field : boundary, field : year : boundary and overwintering : field : year : boundary interactions. 


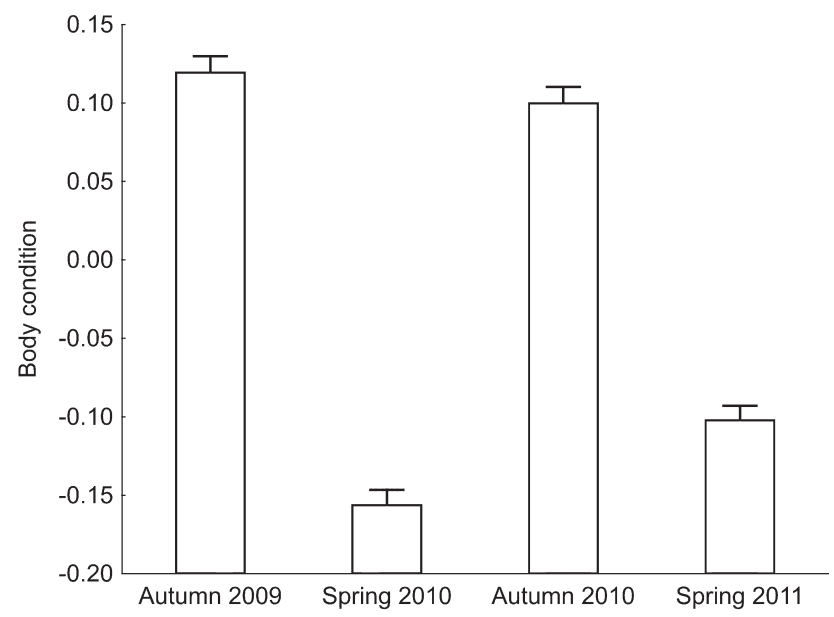

Fig. 2. The effect of overwintering on the body condition of $A$. dorsalis recorded over two winters. To visualise differences in body condition within a season (pre- and post-overwintering) and between seasons (2009/2010 and 2010/2011), residuals from the dry mass-structural body size relationship based on generalised linear model with gamma distribution of errors were used. Mean residuals $+\mathrm{SE}$ are shown.

tion than the post-overwintering individuals collected in spring (Fig. 2). In addition, body condition was significantly affected by sex, as females were in better body condition than males (Fig. 3). The overwintering: sex interaction was also significant (in males the decrease in body condition during overwintering was more substantial than in females; Fig. 3).

The second group of factors affecting body condition are those linked to environmental variability. There was significant variation in the body condition of $A$. dorsalis among particular fields. Body condition also differed slightly between the years (beetles were in better condition in 2010/2011 than in 2009/2010; for differences in the course of temperature between seasons see Appendix A1. In 2009/2010 temperatures below freezing occurred 6 weeks earlier than in 2010/2011 and there were also more frost days in 2009/2010 than in 2010/2011). There were also some significant interactions: overwintering: year (the difference in body condition between pre-overwintering and post-overwintering individuals was greater in 2009/2010 than 2010/2011; Fig. 2), overwintering : field, field: year, field:boundary and some significant higher interactions (see Table 1). It is important to note that the variation explained by the factors linked to environmental variability was rather low (see $\mathrm{R}^{2}$-values reported in Table 1).

\section{DISCUSSION}

Our results indicate that body condition in Anchomenus dorsalis differs significantly between autumn and the subsequent spring, i.e., there is a substantial effect of overwintering. Pre-overwintering specimens were in better body condition than post-overwintering individuals. It is believed that adult carabids preparing for overwintering increase their fat reserves in order to enhance winter survival. However, there is little evidence in the literature in support of this. Individuals of Calathus melanocephalus

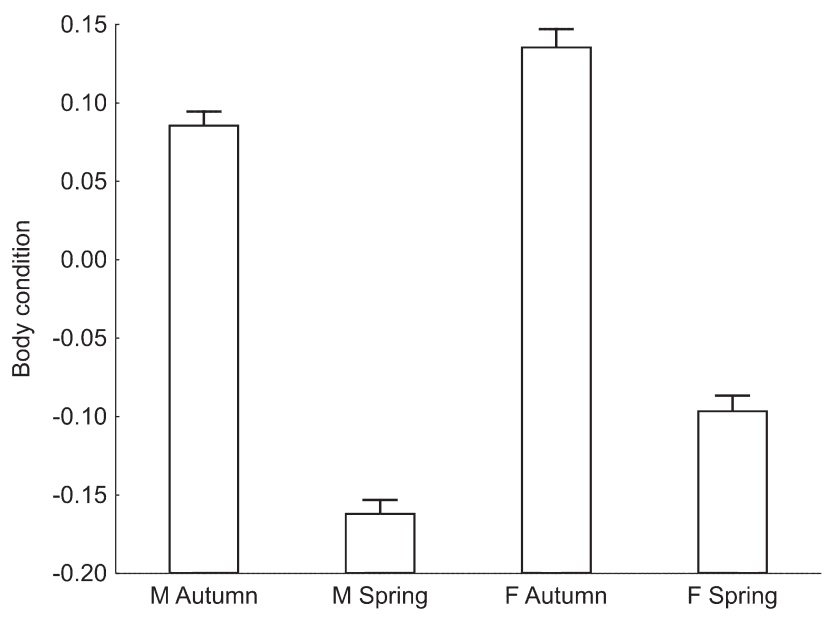

Fig. 3. The effect of sex on the pre- and post-winter body condition of Anchomenus dorsalis. To visualise differences in the preand post-winter body condition between sexes, residuals from dry mass-structural body size relationship based on a generalised linear model with gamma distribution of errors was used. Mean residuals $+\mathrm{SE}$ are shown. $\mathrm{M}$ Autumn $=$ males collected before overwintering; M Spring = males collected after overwintering; $\mathrm{F}$ Autumn $=$ females collected before overwintering; F Spring $=$ females collected after overwintering.

that fed before overwintering, survived better than those that did not, but this was recorded in only one out of two experimental seasons (Van Dijk, 1994). Unfortunately, studies investigating variation in carabid body condition within a season are limited mainly to spring and summer months (den Nijs et al., 1996; Bilde \& Toft, 1998). However, a decrease in body condition during hibernation similar to that recorded in this study is reported by Chaabane et al. (1996) for Abax ater. That A. dorsalis feeds intensively for a few days following emergence from winter diapause, which results in an increase in body mass and lipid content, is recorded (Raubenheimer et al., 2007); however, pre-overwintering body mass and lipid content have not been reported. Small changes in body mass during winter are reported by Petersen at al. (1996) for Bembidion lampros. Interestingly, the decrease in body condition of A. dorsalis during overwintering was more pronounced for beetles collected in 2009/2010 than in 2010/2011. Such inter-annual changes in the decrease in body condition during overwintering could be caused by weather, mainly differences in temperature. Long-term daily temperature fluctuations around freezing $\left(0^{\circ} \mathrm{C}\right)$ causes body mass reduction in Bembidion lampros, whereas constant low temperature does not (Petersen et al., 1996). Thus, the greater reduction in the body condition of overwintering individuals in $2009 / 2010$ may be due to differences in temperature in the two winters (for details see Appendix A1).

Our results also indicate that body condition in $A$. dorsalis differed between sexes. The better body condition of females reported in this study is not surprising as females generally invest much more energy in reproduction than males, and thus selection pressure on female body condition is expected to be higher. Enhanced body condition in post-overwintering females compared to males is also re- 
ported in Bembidion lampros by Knapp \& Saska (2012). Interestingly, post-overwintering females were in a relatively better body condition than males (there was significant interaction between sex and overwintering). A possible explanation of the better ability of females to maintain their body condition over winter lies in their larger body size, as large individuals have proportionally lower metabolism rates than small ones (Glazier, 2005). An alternative explanation is the existence of sex-specific selection pressures on physiological processes or behavioural mechanisms linked to managing energy reserves during winter. Unfortunately, studies investigating sexual dimorphism in the body condition of carabid beetles are lacking, and the link between post-overwintering body condition and subsequent egg production in females needs to be investigated. Currently, high food quality and quantity, resulting in good body condition, are considered to be the main factors affecting egg production in carabid beetles (Sota, 1985; Bilde \& Toft, 1994; van Dijk, 1994; Bommarco, 1998b). The importance of food quality, especially lipid and protein content, for egg production is also recorded specifically for $A$. dorsalis (Jensen et al., 2012). Although A. dorsalis females have better body condition in early spring than males, they still have larger requirements for food before reproduction than males (May to June; Bilde \& Toft, 1998).

In previous studies, the spatially based variation in body condition of carabid beetles within arable fields is reported to be affected by the structure of the surrounding landscape, perimeter-to-area ratio (i.e., shape), farming operations, farming practice (organic vs. conventional) or crop diversity at the landscape level (e.g., Bommarco, 1998b; Östman, 2001; Barone \& Frank, 2003; Frank et al., 2007). Interestingly, in this study, features of the fields and boundary type explained only a very small portion of total variability recorded in the body condition of $A$. dorsalis. This is surprising, as different boundary types are thought to contain different sources of food. For example, body condition in A. dorsalis (species inhabiting open habitats) should be positively affected by a neighbouring grassy boundary in comparison to a forest boundary. There are three possible explanations: (1) our experimental sites are too close to each other, and, thus, the surrounding landscape is similar (shared); (2) our experimental fields did not differ enough in terms of area and shape; (3) all our experimental fields were conventionally managed, with 3 out of 4 fields being managed by the same agricultural company.

Although spatial variation in carabid body condition has been investigated quite intensively, only the study by Östman (2005) investigated spatial variation in carabid body condition over several (two) years. Östman (2005) found that in addition to spatial variation in body condition, there is also substantial temporal variation. Thus, individuals need not have a better body condition in particular fields as the suitability of particular fields for carabids may change from year to year. Such a finding was also confirmed by this study. Asynchronous temporal variation in carabid body condition is most likely caused by variation in environmental conditions e.g., crop rotation or a local pest outbreak as argued by Östman (2005). Unfortunately, the limited scope of our study (just four fields investigated in two subsequent years) does not allow to us to investigate rigorously the effect of the crop and we have no direct information on prey availability at the sites sampled.

In conclusion, the body condition of $A$. dorsalis seems to be affected mainly by strategic factors, which are integrated into the life cycle of this species and thus under the animal's control (e.g., variation in body condition within a season, sex-specific body condition). Environmental factors investigated in this study (year to year variation, field identity and boundary type) were of limited importance in determining its body condition.

ACKNOWLEDGEMENTS. We are grateful to D. Moravec and $\mathrm{K}$. Uhnavá for their assistance with collecting and measuring the beetles. We are grateful to the Crop Research Institute, PragueRuzyně, which allowed us to use their equipment and laboratory facilities, which were necessary to perform this study. We thank two anonymous reviewers for useful comments on an earlier version of this manuscript. This study was financially supported by grants IGA no. 42110/1312/3123 and CIGA no. 43150/1313/3104 awarded by the Czech University of Life Sciences Prague, and Institutional support no. RO0414 awarded by the Ministry of Agriculture.

\section{REFERENCES}

Andersen A. 1997: Densities of overwintering carabids and staphylinids (Col., Carabidae and Staphylinidae) in cereal and grass fields and their boundries. - J. Appl. Entomol. 121: 77-80.

BARANOVSKÁ E. \& KNAPP M. 2014: Small scale spatiotemporal variability in body size of two common carabid beetles. Cent. Eur. J. Biol. 9: 476-494.

BARONE M. \& FRANK T. 2003: Habitat age increases reproduction and nutritional condition in a generalist arthropod predator. Oecologia 135: 78-83.

BILdE T. \& TofT S. 1994: Prey preference and egg rpoduction of the carabid beetle Agonum dorsale. - Entomol. Exp. Appl. 73: 151-156.

BiLde T. \& TofT S. 1997: Consumption by carabid beetles of three cereal aphid species relative to other prey types. - Entomophaga 42: 21-32.

BILDE T. \& ToFT S. 1998: Quantifying food limitation of arthropod predators in the field. - Oecologia 115: 54-58.

BOMMARCO R. 1998a: Reproduction and energy reserves of predatory carabid beetle relative to agroecosystem complexity. Ecol. Appl. 8: 846-853.

Bommarco R. 1998b: Stage sensitivity to food limitation for a generalist arthropod predator, Pterostichus cupreus (Coleoptera: Carabidae). - Environ. Entomol. 27: 864-869.

TER BRAAK C.J.F. \& ŠMILAUER P. 2002: CANOCO Reference Manual and CanoDraw for Windows User's Guide: Software for Canonical Community Ordination (version 4.5). Microcomputer Power, Ithaca.

Chaabane K., Loreau M. \& Josens G. 1996: Individual and population energy budgets of Abax ater (Coleoptera, Carabidae). - Ann. Zool. Fenn. 33: 97-108.

Cotton S., Small J. \& Pomiankowsky A. 2006: Sexual selection and condition-dependent mate preferences. - Curr. Biol. 16: 755-765.

ČÚZK 2014: Prohližecí služba WMS-ortofoto [online]. View Services WMS-ortophoto [last accessed 19 Feb. 2014]. 
Available from: http://geoportal.cuzk.cz/WMS_ORTOFOTO PUB/WMService.aspx?

VAN DIJK T.S. 1994: On the relationship between food, reproduction and survival of two carabid beetles: Calathus melanocephalus and Pterostichus versicolor. - Ecol. Entomol. 19: 263-270.

ELKIN C.M. \& ReID M.L. 2005: Low energy reserves and energy allocation decisions affect reproduction by Mountain Pine Beetles, Dendroctonus ponderosae. - Funct. Ecol. 19: 102-109.

Frank T., Kehrli P. \& Germann C. 2007: Density and nutritional condition of carabid beetles in wildflower areas of different age. - Agr. Ecosyst. Environ. 120: 377-383.

García-Berthou E. 2001: On the misuse residuals in ecology: testing regression residuals vs. the analysis of covariance. $-J$. Anim. Ecol. 70: 708-711.

GLAzIER D.S. 2005: Beyond the '3/4-power law': variation in the intra- and interspecific scaling of metabolic rate in animals. Biol. Rev. 80: 611-662.

Haschek C., Drapela T., Schuller N., Fiedler K. \& Frank T. 2012: Carabid beetle condition, reproduction and density in winter oilseed rape affected by field and landscape parameters. - J. Appl. Entomol. 136: 665-674.

Holland J. 2002: The Agroecology of Carabid Beetle. Intercept, Andover, $356 \mathrm{pp}$.

Holland J.M., Birkett T. \& Southway S. 2009: Contrasting the farm-scale spatio-temporal dynamics of boundary and field overwintering predatory beetles in arable crops. - BioControl 54: $19-33$.

Huusela-Veistola E. 1996: Effects of pesticide use and cultivation techniques on ground beetles (Col., Carabidae) in cereal fields. - Ann. Zool. Fenn. 33: 197-205.

Hůrka K. 1996: Carabidae of the Czech and Slovak Republics. Kabourek, Zlín, 565 pp.

Jensen K., Mayntz D., Toft S., Clissold F.J., Hunt J., RaubenHEIMER D. \& Simpson S.J. 2012: Optimal foraging for specific nutrients in predatory beetles. - Proc. R. Soc. (B) 279: 2212 2218.

Knapp M. 2012: Preservative fluid and storage conditions alter body mass estimation in a terrestrial insect. - Entomol. Exp. Appl. 143: 185-190.

Knapp M. \& KnappovÁ J. 2013: Measurement of body condition in a common carabid beetle, Poecilus cupreus: a comparison of fresh weight, dry weight, and fat content. - J. Insect Sci. 13: 6 .

KNAPP M. \& SASKA P. 2012: The effects of habitat, density, gender and duration on overwintering success in Bembidion lampros (Coleoptera: Carabidae). - J. Appl. Entomol. 136: 225-233.

Löver G.L. \& SunderLand K.D. 1996: Ecology and behavior of ground beetles (Coleoptera: Carabidae). - Annu. Rev. Entomol. 41: 231-256.
Moya-Laraño J. 2002: Senescence and food limitation in a slowly ageing spider. - Funct. Ecol. 16: 734-741.

DEN NiJs L.J.M.F., Lock C.A.M., Noodlander J. \& BoolJ C.J.H. 1996: Search for quality parameters to estimate the condition of Pterostichus cupreus (Col., Carabidae) in view of population dynamic modelling. - J. Appl. Entomol. 120: 147-151.

ÖstMAn Ö. 2005: Asynchronous temporal variation among in condition of two carabid species. - Ecol. Entomol. 30: 63-69.

Östman Ö., Еквом B., Bengtsson J. \& Weibul A. 2001: Landscape complexity and farming practice influence the condition of polyphagous carabid beetles. - Ecol. Appl. 11: 480-488.

Peig J. \& GreEn A.J. 2009: New perspective for estimating body condition from mass/length data: the scaled mass index as an alternative method. _ Oikos 118: 1883-1891.

Peig J. \& Green A.J. 2010: The paradigm of body condition: a critical reappraisal of current methods based on mass and length. - Funct. Ecol. 24: 1323-1332.

Petersen M.K. 1999: Capacity of Bembidion lampros and Tachyporus hypnorum to survive periods of starvation in early spring. - Entomol. Exp. Appl. 90: 207-214.

Petersen M.K., Ekbom B. \& Ravn H.P. 1996: Temperature dependent winter survival of Bembidion lampros and Tachyporus hypnorum. - J. Insect Physiol. 42: 997-1005.

Raubenheimer D., Mayntz D. \& Simpson S.J. \& Toft S. 2007: Nutrient-specific compensation following diapause in a predator: implications for intraguild predation. - Ecology 88: 2598-2608.

R Core Team 2013: R: A Language and Environment for Statistical Computing. Version 3.0.1. Url: http//www.R-project.org.

Roume A., Ouin A., Raison L. \& Deconchat M. 2011: Abundance and species richness of overwintering ground beetles (Coleoptera: Carabidae) are higher in the edge than in the centre of a woodlot. - Eur. J. Entomol. 108: 615-622.

SотA T. 1985: Limitation of reproduction by feeding condition in a carabid beetle, Carabus yaconinus. - Res. Popul. Ecol. 27: 171-184.

WratTEN E.S.D. \& ViCKERMAN G.P. 1985: Foraging by the carabid Agonum dorsale in the field. - Ecol. Entomol. 10: 181-189.

Zaller J.G., Moser D., Drapela T. \& Frank T. 2009: Grounddwelling predators can affect within-field pest insect emergence in winter oilseed rape fields. - BioControl 54: 247-253.

ZANGger A., Lys J.A. \& NenTwIG W. 1994: Increasing the availability of food and the reproduction of Poecilus cupreus in a cereal field by strip-management. - Entomol. Exp. Appl. 70: 111-120.

Received April 23, 2014; revised and accepted August 13, 2014 Prepublished online September 22, 2014 


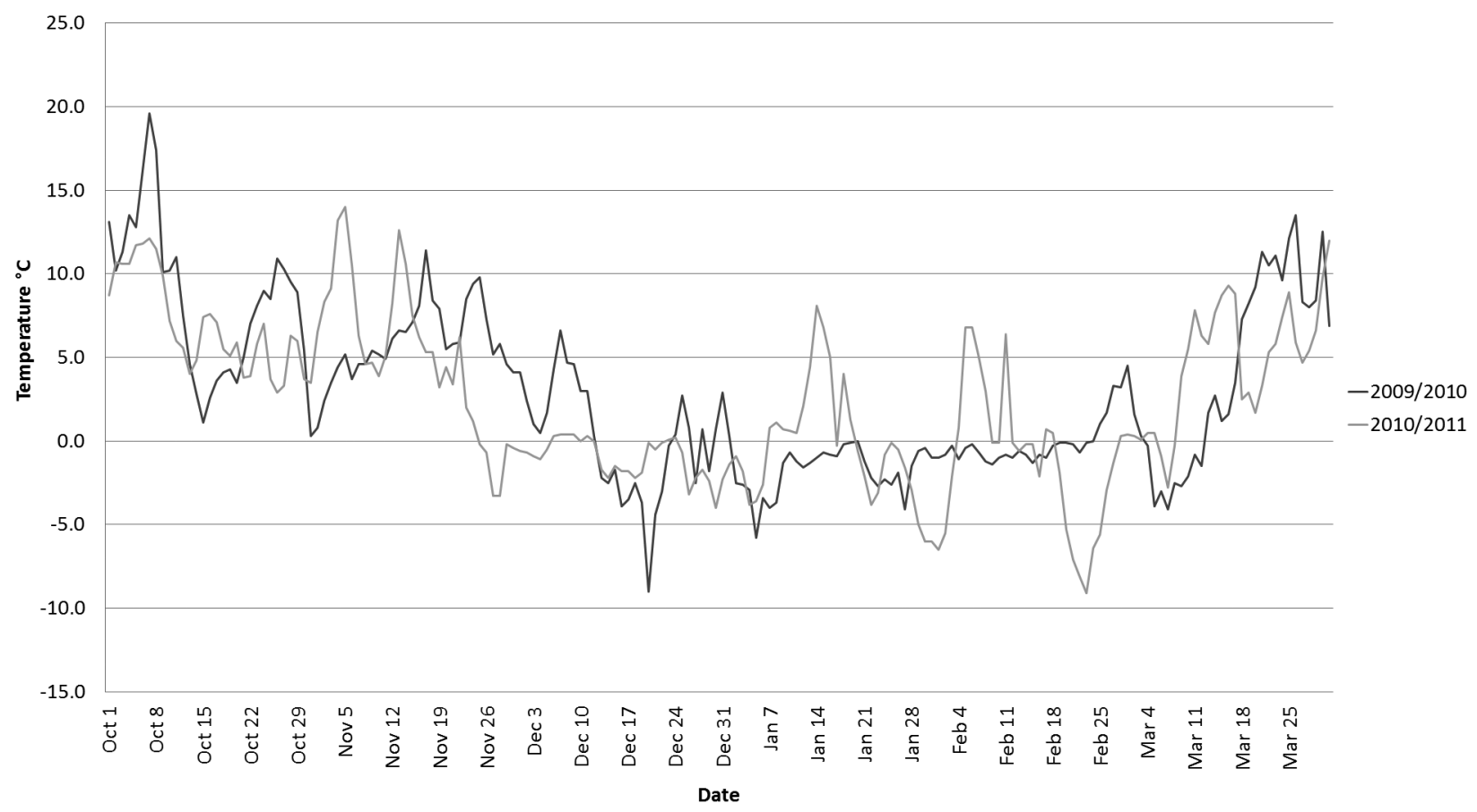

APPENDIX 1. Fluctuations in the average daily temperature from October to March recorded in two consecutive seasons (2009/2010 and 2010/2011). Temperature data were obtained from the weather station of the Crop Research Institute (Prague-Ruzyně). Visualised temperatures represent the temperature measured at the surface of the soil. The black line indicates the course of the average daily temperature recorded in winter 2009/2010 and the grey line that recorded in winter 2010/2011. In winter 2009/2010, there were 59 fluctuations around freezing $\left(0^{\circ} \mathrm{C}\right)$, and in winter $2010 / 2011$, there were 142 fluctuations around freezing. The number of fluctuations around freezing was counted based on hourly measurements of temperature at the surface of the soil. 